\title{
UNIFORM CONVERGENCE ANALYSIS OF FINITE DIFFERENCE METHOD FOR SEMILINEAR SINGULARLY PERTURBED PROBLEMS WITH INTEGRAL BOUNDARY CONDITIONS
}

\author{
Derya Arslan ${ }^{1}$ and musa cakir ${ }^{2}$ \\ ${ }^{1}$ Bitlis Eren Universitesi \\ ${ }^{2}$ Van Yuksek Ihtisas Egitim ve Arastirma Hastanesi
}

April 27, 2020

\begin{abstract}
An convenient numerical method for singularly perturbed problem with integral boundary conditions is proposed by using finite difference method. Firstly, the evaluations of the exact solution are given. Then difference scheme is constructed in Shishkin mesh. Finally, the convergence analysis of this method is done and obtained first order uniformly convergence with respect to perturbation parameter in discrete maximum norm. Numerical results are presented in support of the proposed method.

Hosted file m. cakir and d. arslan.pdf available at https://authorea.com/users/315200/articles/445564uniform-convergence-analysis-of-finite-difference-method-for-semilinear-singularly-perturbed-problems-with-integralboundary-conditions
\end{abstract}


figures/seps1/seps1-eps-converted-to.pdf 